\title{
Head morphometry and chromatin instability in normal boar spermatozoa and in spermatozoa with cytoplasmic droplets
}

\author{
Thais Schwarz Gaggini ${ }^{1}$, Lays Oliveira Rocha, Elisson Terêncio Souza, Fernanda Marcondes de Rezende, \\ Robson Carlos Antunes, Marcelo Emílio Beletti
}

Universidade Federal de Uberlândia (UFU), Uberlândia, Minas Gerais, Brazil.

\begin{abstract}
In boar studs, morphological analyses are used to evaluate sperm quality and thereby categorize ejaculates as either approved or rejected. Normally, morphological characteristics correlate with chromatin disorders, but studies to date have only considered the average of abnormalities; cells were not segregated as normal or abnormal. The aim of this study was to assess whether the presence of cytoplasmic droplets was associated with morphometric characteristics and chromatin instability of spermatozoa heads. Morphological analyses were performed on semen from 11 boars using phase contrast microscopy (200 cells per sample). Normal cells were differentiated from those with cytoplasmic droplets and both types were evaluated separately. Photomicrographs were acquired of normal spermatozoa (Group NOR, N = 1,207) as well as spermatozoa with proximal and distal cytoplasmic droplets (Group DROP, N = 725). Sperm-head morphometry and chromatin structure were evaluated using the toluidine blue technique. Spermatozoa heads in the DROP group were longer $(8.37 \pm 0.60 \times 8.31 \pm 0.53 ; \mathrm{P}=0.025)$, narrower $(4.16 \pm 0.21 \times 4.19 \pm 0.19 ; \mathrm{P}=0.03)$, and more symmetric on the sides $(0.973 \pm 0.012 \times 0.971 \pm 0.011$; $\mathrm{P}=0.007)$ than were spermatozoa heads of the NOR group. The DROP group also had a greater average ellipticity $(0.335 \pm 0.034 \times 0.329 \pm 0.031 ; \mathrm{P}=0.0004)$, a greater percentage of decondensed chromatin $(2.71 \pm 3.87 \times 2.28 \pm 1.38 ; \mathrm{P}<0.0008)$, and a greater chromatin heterogeneity $(4.66 \pm 1.40 \times 4.40 \pm 1.42$; $\mathrm{P}<0.0001)$. A greater frequency of semen collection results in a shorter period of cell maturation and this probably affected the degree of chromatin condensation and the cytoplasmic droplet migration, with concomitant effect on the head morphometry measurements. In conclusion, compared with normal spermatozoa, those with cytoplasmic droplets show altered morphometric characteristics, such as longer and narrower spermatozoa heads. They likewise have greater chromatin instability, resulting in a higher percentage of decondensed chromatin and more heterogeneous chromatin.
\end{abstract}

Keywords: decondensed chromatin, cytoplasmic droplet, boar semen, morphology, morphometry.

\section{Introduction}

During sperm maturation in the epididymis, cytoplasmic droplets migrate from the head to the tail, and they are released when spermatozoa mature
(Cooper and Yeung, 2003; Briz et al., 1995). Generally, in systems with intensive semen collection, immature sperm can be released in the ejaculate because the time for droplet migration is reduced. An important characteristic of such immature cells is the presence of proximal (PCD) and distal (DCD) cytoplasmic droplets in the sperm tail (Flowers, 2004).

The spermatozoa head, the mid-piece, and the tail develop concurrently (Gil et al., 2009); therefore, it has been hypothesized that the presence of cytoplasmic droplets is associated with abnormal head measurements and chromatin instability. Spermatozoa head morphometry has shown that some of these measurements correlate with female reproductive performance (Hirai et al., 2001), with chromatin destabilization (Hingst et al., 1995; Karabinus et al., 1997), and with the presence of abnormalities in the ejaculate (Gaggini et al., 2015). However, few data support this hypothesis, and spermatozoa head morphometry is not routinely performed in the field during semen evaluation.

In order to prevent ejaculates bearing a high percentage of immature cells from being incorporated into artificial insemination doses, morphological tests are performed monthly in ejaculates of all boars or every 50-60 days in boar studs. Ejaculates with more than $10 \%$ of cells showing PCD are deemed unsuitable (Feitsma, 2009). A high percentage of DCD is not a cause for rejection, but it also indicates immaturity of sperm (Saravia et al., 2007). Thus, rejection of ejaculates with more than 10\% PCD and DCD is a sound approach, because the presence of cytoplasmic droplets is negatively correlated with pregnancy rate and litter size (Waberski et al., 1994).

It is not possible to identify, through morphological tests alone, certain sperm alterations responsible for a reduction in fertilization rate or increased embryonic mortality. Altered chromatin compaction has been studied and is known to be one factor responsible for low male fertility or subfertility in humans (Liu and Backer, 1992; Spano et al., 2000; Bungum et al., 2004) as well as in boars (Boe-Hansen et al., 2008). In bulls (Januskauskas et al., 2003; Khalil, 2004), altered chromatin compaction reduces fertility even when sperm motility and morphology results are considered acceptable (Beletti and Mello, 1996).

While several studies have used samples from bulls and humans (Januskauskas et al., 2003; Bungum et al., 2004; Lucio et al., 2016), few have correlated sperm morphology and chromatin instability in swine (Saravia et al., 2007; Tsakmakidis et al., 2010). Further, many 
studies that correlated morphological data with chromatin instability did not distinguish normal cells from those with cytoplasmic droplets, therefore, it is not possible to determine whether the presence of cytoplasmic droplets is related to chromatin instability. Thus, the aim of the study was to assess whether cytoplasmic droplets are associated with altered morphometric characteristics and chromatin instability in boar spermatozoa.

\section{Materials and Methods}

Boars from the same genetic line $(n=11$, hybrid line - Pietrain x Large White $\mathrm{x}$ Landrace - from the same boar stud) were sampled and one ejaculate was obtained from each animal. The average age of the animals on the day of sample collection was $585.95 \pm 108.25$ days and the average collection interval (defined as the average number of days between the last collection and the day of sample collection) was $5.59 \pm 1.80$ days. All animals were given ad libitum access to water and fed $2.5 \mathrm{~kg} / \mathrm{d}$ cornsoybean diet containing $0.55 \%$ digestible lysine and $3300 \mathrm{kcal}$ metabolizable energy. Environmental temperature of the boar stud was controlled to a maximum of $22^{\circ} \mathrm{C}$.

Semen from the boars was collected using the glove-hand technique (Hancock and Hovel, 1959) in a pre-warmed $\left(36^{\circ} \mathrm{C}\right)$ plastic bag equipped with a filter to remove the gel fraction and collect only the rich fraction. Ejaculates were evaluated macroscopically for color, aspect, temperature, volume, and odor, and microscopically by subjective evaluation for sperm motility by the same technician. Only semen samples with a minimum of $85 \%$ motile cells were approved.

Semen samples approved in motility assessment were then prepared in Eppendorf tubes using an electronic mixing pipette such that $0.5 \mathrm{~mL}$ of semen was diluted with $2 \mathrm{~mL}$ of warm $\left(36^{\circ} \mathrm{C}\right)$ buffered formalin. These samples were used for morphological examination, morphometric measurements, and chromatin instability evaluation. All samples were analyzed no later than $72 \mathrm{~h}$ after semen collection.

The morphological examination was performed in a phase contrast microscope at $100 \times$ magnification using an oil immersion lens. Two hundred spermatozoa from each sample were classified according to sperm morphology as normal, or with acrosome defect, abnormal head, neck defect, midpiece defect, folded tail, coiled tail, PCD, or DCD (Pursel et al., 1972). All samples used in the study presented at least one cytoplasmic droplet count.

The morphometric and chromatin instability examinations were performed following the protocol of Beletti et al. (2005). Briefly, one droplet of each sample was smeared onto a glass slide, dried, hydrolyzed with 4N $\mathrm{HCl}$ for $15 \mathrm{~min}$, washed three times with distilled water, dried, stained with one droplet of blue toluidine $(0.025 \%$, pH 4 , in McIlvaine buffer), and covered with a cover slip after one minute. Pictures of spermatozoa were acquired on a microscope (Leica DM500 with Leica ICC50 digital camera). Stained slides were photographed at $100 \times$ magnification with oil immersion. Normal cells
(NOR group) and cells with cytoplasmic droplets (DROP group) were photographed separately; the pictures of each sample (separate by animals) and each group (NOR and DROP) were saved in different folders such that during analyses it was possible to see each cell from each boar and assess whether the cells were normal or had cytoplasmic droplets. The number of cells used per boar in NOR and DROP groups were defined by the number of cells that had no overlap with other cells or with dirt.

Head segmentation was assessed by a semiautomatic method and was performed on 1,207 heads of the NOR group (average of 109.72 \pm 38.74 per boar with minimum value of 61 and maximum value of 162 ), and 725 heads of the DROP group (average of $68.63 \pm 56.99$ per boar with minimum value of 7 and maximum value of 161). Heads were evaluated using algorithms developed in Scilab (Beletti et al., 2005). Parameters evaluated were area, perimeter, width, length, ratio of width to length, ellipticity (e), and shape factor (SF). Ellipticity is defined as elongation of the head contour: (length - width) / (length + width), normalized to $-1<\mathrm{e}<1$ (Beletti and Costa, 2003). Shape factor is defined as degree of deviation of the head contour from a smooth ellipse: $(1-\mathrm{e}) \times$ perimeter $^{2}$ $14 \pi \times$ area (Beletti and Costa, 2003). Additional parameters were side symmetry (identifies asymmetries along the principal spermatozoa axis) and anteriorposterior symmetry (identifies asymmetry along the secondary spermatozoa axis). These were calculated by flipping the heads along their major and minor axis, filling the voids obtained by the orthogonal lattice representation of the head, and then identifying the intersection between the original and flipped areas (Beletti et al., 2005).

The algorithm also evaluated pixels of each head and selected 20 heads with minor standard deviation from each sample. From these 20 selected heads, the algorithm then selected six with the maximum average of pixel values (faintly stained heads) because those six heads theoretically represented the cells with the most compacted chromatin. The average values of these cells were considered as the default value for all heads of that sample. Next, the algorithm calculated the difference between the default value and the value of each photographed head of the same sample, then converted this difference to percent thereby yielding the percentage of decondensed chromatin. The coefficient of variation for the gray scale intensity value of each head was also calculated, which represents the heterogeneity of chromatin condensation (Beletti et al., 2005).

All analyses were performed with Statistical Analysis System, version 9.1.3 (SAS Institute, 2005). Head spermatozoa were the experimental unit for the analyses. All parameters were analyzed using the general linear model (GLM procedure) considering individual boar effect and age at collection as covariates. Correlation test (CORR procedure) was used to evaluate relationships between percentage of cytoplasmic droplets in ejaculate (obtained in morphological exam), morphometric values, and 
chromatin characteristics. Differences were considered as significant at $\mathrm{P}<0.05$.

\section{Results}

Spermatozoa heads from the NOR group were wider than those in the DROP group $(\mathrm{P}=0.030)$, while DROP spermatozoa heads were longer than NOR heads $(\mathrm{P}=0.025)$. The higher width-to-length ratio of NOR spermatozoa heads $(P=0.005)$ further confirmed the observation that NOR heads were wider and shorter than DROP heads. Similarly, ellipticity results confirmed that DROP heads were more elongated than NOR heads $(P=0.0004)$, and shape factor analysis likewise indicated that NOR heads were more similar to an ellipse than were DROP heads $(\mathrm{P}=0.018$; Table 1$)$. Compared to NOR heads, DROP heads were more symmetric on the sides $(\mathrm{P}=0.007)$, but no difference was seen in anterior-posterior symmetry $(\mathrm{P}=0.430)$. Chromatin heterogeneity and percent decondensed chromatin were higher in the DROP group than in the NOR group $(\mathrm{P}<0.001$ for both).

Table 1. Morphometric measurements, percentage of decondensed chromatin and chromatin heterogeneity of the boar sperm heads of normal sperm and sperm with proximal or distal cytoplasmic droplets (Mean \pm Standard Deviation).

\begin{tabular}{lccc}
\hline Variables & DROP & NOR & $\mathrm{p}$ \\
\hline Number of cells & 725 & 1207 & 0.897 \\
Head area, $\mu \mathrm{m}^{2}$ & $44.81 \pm 3.66$ & $44.78 \pm 3.54$ & 0.423 \\
Head perimeter, $\mu \mathrm{m}$ & $22.10 \pm 1.29$ & $22.06 \pm 1.15$ & 0.030 \\
Head width, $\mu \mathrm{m}$ & $4.16 \pm 0.21^{\mathrm{a}}$ & $4.19 \pm 0.19^{\mathrm{b}}$ & 0.025 \\
Head length, $\mu \mathrm{m}$ & $8.37 \pm 0.60^{\mathrm{a}}$ & $8.31 \pm 0.53^{\mathrm{b}}$ & 0.005 \\
Width:Length ratio & $0.50 \pm 0.04^{\mathrm{a}}$ & $0.51 \pm 0.34^{\mathrm{b}}$ & 0.0004 \\
Head ellipticity & $0.335 \pm 0.034^{\mathrm{a}}$ & $0.329 \pm 0.031^{\mathrm{b}}$ & 0.018 \\
Shape factor & $0.901 \pm 0.039^{\mathrm{a}}$ & $0.906 \pm 0.033^{\mathrm{b}}$ & 0.007 \\
Side symmetry & $0.973 \pm 0.012^{\mathrm{a}}$ & $0.971 \pm 0.011^{\mathrm{b}}$ & 0.430 \\
Anterior-posterior symmetry & $0.959 \pm 0.026$ & $0.960 \pm 0.022$ & $2.28 \pm 1.38^{\mathrm{b}}$ \\
Decondensed chromatin, $\%$ & $2.71 \pm 3.87^{\mathrm{a}}$ & $4.40 \pm 1.42^{\mathrm{b}}$ & 0.0008 \\
Chromatin heterogeneity, $\%$ & $4.66 \pm 1.40^{\mathrm{a}}$ & $<0.0001$ \\
\hline
\end{tabular}

NOR - heads of normal sperm (without abnormalities); DROP - heads of sperm with proximal or distal cytoplasmic droplet. $^{\mathrm{a}, \mathrm{b}}$ indicate statistical difference between groups.

Significant correlations were found among percent decondensed chromatin, chromatin heterogeneity, and all morphometric measurements except ante posterior symmetry and chromatin heterogeneity (Table 2). Chromatin heterogeneity was also correlated with percent decondensed chromatin, and both parameters were significantly correlated with percent cytoplasmic droplets.

Table 2. Correlation among percentage of decondensed chromatin, morphometric measurements and chromatin heterogeneity of boar sperm.

\begin{tabular}{lcccc}
\multicolumn{1}{c}{ Morphometric measurements } & \multicolumn{2}{c}{ Decondensed chromatin } & \multicolumn{2}{c}{ Chromatin heterogeneity } \\
& $\mathrm{r}$ & $\mathrm{p}$-value & $\mathrm{r}$ & $\mathrm{p}$-value \\
\hline Head area & 0.31 & $<0.0001$ & 0.51 & $<0.0001$ \\
Head perimeter & 0.25 & $<0.0001$ & 0.44 & $<0.0001$ \\
Head width & 0.23 & $<0.0001$ & 0.38 & $<0.0001$ \\
Head length & 0.21 & $<0.0001$ & 0.35 & $<0.0001$ \\
Width to length ratio & -0.04 & 0.007 & -0.09 & $<0.0001$ \\
Ellipticity & 0.05 & 0.006 & 0.09 & $<0.0001$ \\
Shape factor & -0.10 & $<0.0001$ & -0.14 & $>0.0001$ \\
Lateral symmetry & 0.08 & $<0.0001$ & 0.18 & $<0.0001$ \\
Ante posterior symmetry & 0.05 & 0.002 & 0.01 & 0.450 \\
Cytoplasmic droplets, \% & 0.06 & 0.001 & 0.22 & $<0.0001$ \\
Chromatin heterogeneity & 0.35 & $<0.0001$ & - & - \\
\hline
\end{tabular}

$\mathrm{r}=$ correlation coefficient values

\section{Discussion}

Studies in other species have shown that variation in spermatozoa morphology is a sensitive marker of chromatin abnormality and animal fertility
(Hingst et al., 1995; Karabinus et al., 1997; Beletti et al., 2005). Thus, in the present study, normal spermatozoa and spermatozoa with cytoplasmic droplets were evaluated separately. To the best of our knowledge, this is the first report of such an evaluation; 
no comparable results exist in the literature. Nonetheless, studies that have compared rejected and approved ejaculates based on sperm morphological examination have shown results similar to those reported here. A positive correlation $(\mathrm{r}=0.44 ; \mathrm{P}=0.01)$ between decondensed chromatin and percent cytoplasmic droplets has been reported (Martínez, 2005) based on the sperm chromatin structure assay (SCSA): a modified fluorescence microscopy assay. Fischer et al. (2003) also showed a positive correlation $(\mathrm{r}=0.59, \mathrm{P}<0.001)$ between DNA denaturation and the presence of cytoplasmic droplets in human sperm using flow cytometry analysis of acridine-orange-treated spermatozoa. Further, Volker (2004) reported that when the occurrence of cytoplasmic droplets is higher than $50 \%$ in boars, the presence of decondensed chromatin is greater than 5\%. However, we report a comparatively smaller but significant difference in percent decondensed chromatin. No defined limits for percent decondensed chromatin exist, but previous reports have used 5\% (Wabersky et al., 2002; Volker, 2004; Martínez, 2005). We showed that sperm from NOR and DROP groups both were within this limit, and it is important to consider the differences in methodologies, genetic lines and species used in our study compared to those in literature.

Several methodologies exist for evaluation of chromatin stability: SCSA, Feulgen test, single-cell gel electrophoresis (Comet), terminal deoxinucleotidyl transferase-mediated dUTP nick-end labeling (TUNEL) assay, acridine orange test, sperm chromatin dispersion test (SCD), aniline blue staining, and toluidine blue staining (Erenpreiss et al., 2001; Bungum, 2012; Beletti, 2013). Despite differences between these techniques, their results are moderately to strongly positively correlated among each other (Erenpreiss et al., 2001; Beletti and Mello, 2004; Erenpreiss et al., 2004; Bungum, 2012). Among these tests, SCSA is the most used (Beletti, 2013), but its high cost lowers its practical applicability. The toluidine blue technique is easy and inexpensive (Beletti and Mello, 2004; Erenpreiss et al., 2004), and it has been used for chromatin stability evaluation of many species: humans (Erenpreiss et al., 2001; Beletti and Costa, 2003; Erenpreiss et al., 2004), rabbit (Beletti and Mello, 2004), bovine, caprine, ovine, canine (Beletti and Costa, 2003), fowl (Rodrigues et al., 2009), equine (Naves et al., 2004) and porcine (Arraztoa et al., 2016). The toluidine blue technique was chosen for the present study because spermatozoa head morphology, morphometry, and chromatin can all be evaluated concomitantly, as described by Beletti et al. (2005).

Although most correlations were statistically significant, correlation coefficient (r) values were considered low and, for this reason, only the highest values are considered in this discussion. Moreover, it is not possible to include individual boar effect and age as covariates in the correlation test; thus, some correlation values could be influenced by these characteristics. Chromatin heterogeneity was correlated with the percent decondensed chromatin, which indicates that cells with abnormal chromatin have greater heterogeneity in chromatin compaction within the spermatozoa head. In agreement with the results reported by Beletti et al. (2005) for bulls, correlations among chromatin heterogeneity, decondensed chromatin, and head morphometric measurements reported here indicate that chromatin condensation can be associated with sperm head morphometry even in the absence of morphological abnormalities. The positive correlation between percent cytoplasmic droplets and chromatin heterogeneity can possibly be explained by the immaturity of cells when they were ejaculated. More frequent semen collection results in less time for cell maturation, and this probably influences the completion of chromatin condensation (Yoseffi et al., 1994; Hingst et al., 1995; Golan et al., 1996) as well as cytoplasmic droplet migration (Flowers, 2004). Also important is that retention of droplets, primarily proximal droplets, correlates strongly with production of reactive oxygen species (ROS) in semen (Gomez et al., 1996). ROS has been shown to affect sperm function in different ways, which include impaired fertilization capacity and DNA integrity (Irvine et al., 2000; Aitken and De Iuliis, 2010; Aitken et al., 2013).

Hirai et al. (2001) studied sperm of Pietrain boars using automated sperm morphometry analysis (ASMA); Saravia et al. (2007) used ASMA and the ISAS ${ }^{\circ}$ morphometric module to evaluate sperm of Duroc, Large White, Landrace, and hybrid lines; and Gil et al. (2009) used ISAS ${ }^{\circ}$ to evaluate sperm from Iberian boars. All these studies reported lower average head area $\left(28.45-36.20 \mu^{2}\right)$ than that in the present study, but Saravia et al. (2007) showed higher values for average head perimeter $(26.00 \mu \mathrm{m})$, width $(4.50$ $\mu \mathrm{m})$, length $(9.00 \mu \mathrm{m})$, and ellipticity (2.00). Similarly, Gil et al. (2009) reported greater values for head perimeter $(22.35 \mu \mathrm{m})$ and ellipticity (1.99), but lower values for head width $(4.07 \mu \mathrm{m})$ and length $(8.11 \mu \mathrm{m})$ than those reported here. Importantly, it has been shown that differences in measurements arise dependent on the boar lines (Saravia et al., 2007; Kondracki et al., 2012) and evaluation technique (Boersma et al., 1999). Therefore, we propose that morphometric data should be compared between studies only when the analysis method and the boar genetic line are identical.

We found that ellipticity and shape factor are in agreement with width and length, which show that the DROP group sperm heads were more elongated than those of the NOR group. Symmetry measurements relate to hydrodynamic properties of the cell and can therefore be used for identification of specific alterations in sperm heads, such as the pyriform head (Beletti and Costa, 2003). Even though cells in the DROP group did not demonstrate head abnormalities, the average for side head symmetry in this group was higher than for the NOR group. This implies that the presence of droplets could be associated with head shape.

Very few studies have analyzed the effects of sperm head morphometric measurements on the reproductive performance of sows. Hirai et al. (2001) showed that sows inseminated with semen containing longer sperm heads had a reduced farrowing rate, and 
the cutoff value in their analysis was $86 \%$. Even though the present study did not evaluate the effect of cytoplasmic droplet presence on the reproductive performance of sows, the results of the morphometric analyses were similar in both studies, i.e., longer sperm produced poorer results. This similarity can be explained by the relationship between sperm head morphology and fertility potential. Accordingly, we showed that cells with cytoplasmic droplets have longer heads and, when present during morphological exam, this abnormality is generally negatively correlated with reproductive performance (Waberski et al., 1994; Benchaib et al., 2003; Feitsma et al., 2008; Feitsma, 2009; McPherson et al., 2014).

In conclusion, in abnormal sperm, the presence of cytoplasmic droplets is associated not only with altered morphometric characteristics (in particular, longer and narrower sperm heads) but also with chromatin instability (higher percent decondensed chromatin and more heterogeneous chromatin).

\section{Acknowledgements}

The authors are grateful to $\mathrm{CNPq}$ and FAPEMIG and CAPES Brazilian agencies for financial support.

\section{References}

Aitken RJ, De Iuliss GN. 2010. On the possible origins of DNA damage in human spermatozoa. Mol Hum Reprod, 16:3-13.

Aitken RJ, Bronson R, Smith TB, De Iuliis GN. 2013. The source and significance of DNA damage in human spermatozoa; a commentary on diagnostic strategies and straw man fallacies, Mol Hum Reprod, 19:475-485.

Arraztoa CC, Miragaya MH, Chaves MG, Trasorras VL, Gambarotta MC, Péndola CH, Neild DM. 2016. Porcine sperm vetrification I: cryoloops method. Androlog, 49. Doi: 10.1111/and.12706.

Beletti ME. 2013. Cromatina espermática: quebrando paradigmas. Rev Bras Reprod Anim, 37:2, 92-96.

Beletti ME, Costa LF. 2003. A systematic approach to multi-species sperm morphometrical characterization. Anal Quant Cytol Histol, 25:97-107.

Beletti ME, Costa LF, Guardieiro MM. 2005 Morphometric features and chromatin condensation abnormalities evaluated by toluidine blue staining in bull spermatozoa. Braz J Morphol Sci, 22:85-90.

Beletti ME, Mello MLS. 2004. Comparison between the toluidine blue stain and the Feulgen reaction for evaluation of rabbit sperm chromatin condensation and their relationship with sperm morphology. Theriogenology, 62:298-402.

Beletti ME, Mello MLS. 1996. Methodological variants contributing to detection of abnormal DNA: protein complexes in bull spermatozoa. Braz J Genet, 19:97-103.

Benchaib M, Braun V, Lornage J, Hadj S, Salle B, Lejeune H, Guérin JF. 2003. Sperm DNA fragmentation decreases the pregnancy rate in an assisted reproductive technique. Hum Reprod, 18:1023-
1028.

Boe-Hansen GB, Christensen P, Vibjerg D, Nielsen MBF, Hedeboe AM. 2008. Sperm chromatin structure integrity in liquid stored boar semen and its relationships with field fertility. Theriogenology, 69:728-736.

Boersma AA, Braun J, Stolla R. 1999. Influence of random factors and two different staining procedures on computer-assisted sperm head morphometry in bulls. Reprod Dom Anim, 34:77-82.

Briz MD, Bonet S, Pinart B, Egozcue J, Camps R. 1995. Comparative study of boar sperm coming from the caput, corpus, and cauda regions of the epididymis. $J$ Androl, 16:175-88.

Bungum M. 2012. Sperm DNA integrity assessment: a new tool in diagnosis and treatment of fertility. Obstet Gynecol Int, 2012. Doi.org/10.1155/2012/531042.

Bungum M, Humaidan P, Spano M, Jepson K, Bungum L, Giwercman A. 2004. The predictive value of sperm chromatin assay (SCSA) parameters for the outcome of intrauterine insemination, IVF and ICSI. Hum Reprod, 19:1401-1408.

Cooper TG, Yeung CH. 2003. Acquisition of volume regulatory response of sperm upon maturation in the epididymis and the role of the cytoplasmic droplet. Microsc Res Techniq, 61:28-38.

Erenpreiss J, Bars J, Lipatnikova V, Erenpreisa J, Zalkalns J. 2001. Comparative study of citochemical tests for sperm chromatin integrity. J Androl, 22:45-53.

Erenpreiss J, Jepson J, Giwercman A, Tsarev I, Erenpreisa J, Spano M. 2004. Toluidine blue cytometry test for sperm DNA conformation: comparison with the flow cytometric sperm chromatin structure and TUNEL assays. Hum Reprod, 19:22772282.

Feitsma H, Bergsma R, Leenhouwers JI, Knol EF. 2008. Combining AI and Breeding Databases for Analysing the Relation between Boar Semen and Sow Fertility Variables. Reprod Dom Anim, 43:57-58.

Feitsma H. 2009. Artificial insemination in pigs, research and developments in The Netherlands, a review. Acta Sci Vet, 37:61-71.

Flowers WL. 2004. Detailed description of sperm motility/morphology and causes of abnormalities. In Abstracts of the Midwest Boar Stud Conference II, 2004, St Louis, USA, p.15-22.

Fischer MA, Willis J, Zini A. 2003. Human sperm DNA integrity: correlation with sperm cytoplasmic droplets. Urology, 61:207-2011.

Gaggini TS, Rocha LO, Moura TS, Antunes RC, Beletti ME. 2015. Spermatic morphometry of boars approved and reproved in spermatic morphology test [In Portuguese]. In Abstracts of the XVII Congresso da Associação Brasileira de Veterinários Especialistas em Suínos, 2015, Campinas, Brazil. Campinas: ABRAVES, p.448-450.

Gil MC, García-Herreros M, Aparicio IM, Santos AJ, García-Marín LJ. 2009. Morphometry of porcine spermatozoa and its functional significance in relation with the motility parameters in fresh semen. Theriogenology, 71:254-263.

Golan R, Cooper TG., Oschry Y, Oberpenning F, 
Schulze H, Shochat L, Lewin LM. 1996. Changes in chromatin condensation of human spermatozoa during epididymal transit as determined by flow cytometry. Hum Reprod, 11:1457-1462.

Gomez E, Buckingham DW, Brindle J, Lanzafame F, Irvine DS, Aitken RJ. 1996. Development of an image analysis system to monitor the retention of residual cytoplasm by human spermatozoa: correlation with biochemical markers of the cytoplasmic space, oxidative stress, and sperm function. $J$ Androl, 17:276-287.

Hancock JL, Hovel GLR. 1959. The collection of boar semen. Vet Rec, 71:664-665.

Hingst O, Blottner S, Franz C. 1995. Chromatin condensation in cat spermatozoa during epididymal transit as studied by aniline blue and acridine orange staining. Andrology, 27:275-279.

Hirai M, Boersma A, Hoeflich A, Wolf E, Foll J, Aumüller TR, Braun J. 2001. Objectively measured sperm motility and sperm head morphometry in boars (Sus scrofa): relation to fertility and seminal plasma growth factors. $J$ Androl, 22:104-10.

Irvine DS, Twigg JP, Gordon E, Fulton N, Milne PA, Aitken RJ. 2000. DNA integrity in human spermatozoa: relationships with semen quality. $J$ Androl, 21:33-44.

Januskauskas A, Johannisson A, RodríguezMartínez H. 2003. Subtle membrane changes in cryopreserved bull semen in relation with sperm viability, chromatin structure, and field fertility. Theriogenology, 60:743-758.

Karabinus DS, Vogler CJ, Saacke RG, Evenson DP. 1997. Chromatin structural changes in sperm after scrotal insulation of Holstein bulls. J Androl, 18:549-555.

Khalil Y. 2004. Binding capacity of bull spermatozoa to oviductal epithelium in vitro and its relationship to sperm chromatin stability, sperm volume regulation and fertility. (thesis). Hanover, Germany: School of Veterinary Medicine Hannover.

Kondracki S, Iwanina M, Wysokińska A, Huszno M. 2012. Comparative analysis of Duroc and Pietrain boar sperm morphology. Acta Vet, 81:195-199

Liu DY, Baker HWG. 1992. Sperm nuclear chromatin normality: relationship with sperm morphology, spermzona pellucida binding, and fertilization rates in vitro. Fertil Steril, 58:1178-1184.

Lucio AC, Alves BG, Alves KA, Martins MC, Braga LS, Miglio L, Alves BG, Silva TH, Jacomini JO, Beletti ME.2016. Selected sperm traits are simultaneously altered after scrotal heat stress and play specific roles in in vitro fertilization and embryonic development. Theriogenology, 86(4):924-933.
Martinez FA. 2005. Studies on the interaction of chromatin-unstable boar sperm with the female reproductive tract. (thesis). Hannover, Germany: University of Veterinary Medicine Hannover.

McPherson FJ, Nielsen SG, Chenoweth PJ. 2014. Semen effects on insemination outcomes in sows. Anim Reprod Sci, 151:28-33.

Naves CS, Beletti ME, Duarte MB, Vieira RC, Diniz EG, Jacomini JO. 2004. Evaluation of equine spermatic chromatin with toluidine blue and acridine orange. Biosci J, 20(3):117-124.

Pursel VG, Johnson LA, Rampacek GB. 1972. Acrosome morphology of boar spermatozoa incubated before cold shock. J Anim Sci, 34:278-283.

Rodrigues ACN, Rocha JV, Beletti ME. 2009. Análise computacional da compactação da cromatina de espermatozoides de galo. Arq Bras Med Vet Zootec, 61(6):1302-1307.

Saravia F, Núnez-Martínez I, Morán JM, Soler C, Muriel A, Rodríguez-Martínez H, Penã FJ. 2007. Differences in boar sperm head shape and dimensions recorded by computer-assisted sperm morphometry are not related to chromatin integrity. Theriogenology, 68:196-203.

SAS Institute. 2005. SAS User's Guide, Release 9.1.3. SAS Institute, Cary, NC.

Spano M, Bonde JP, Hjøllund HI, Kolstad HA, Cordelli E, Leter G. 2000. Sperm chromatin damage impairs human fertility. Fertil Steril, 73(1):43-50.

Tsakmakidis IA, Lymberopoulos AG, Khalifa TA. 2010. Relationship between sperm quality traits and field-fertility of porcine semen. J Vet Med Sci, 11:151154.

Volker G. 2004. Untersuchungen zur Verbesserung der In-vitro-Diagnostik von Eberspermien und Ermittlung der Beziehung zum Befruchtungserfolg. [in German]. (Thesis). Hanover, Germany: School of Veterinary Medicine Hannover.

Waberski D, Helms D, Beyerbach M, Weitze KF, Bollwein H, Bluemig P, Willeke H, Acevedo N, Saacke RG. 2002. Sperm chromatin structure in boars used in artificial insemination. Reprod Dom Anim, 37:257.

Waberski D, Meding S, Dirksen G, Weitze KF, Leiding C, Hahn R. 1994. Fertility of long-term-stored boar semen: influence of extender (Androhep and Kiev), storage time and plasma droplets in the semen. Anim Reprod Sci, 36:145-151.

Yoseffi S, Oschry Y, Lewin LM. 1994. Chromatin condensation in hamster sperm: a flow cytometric investigation. Mol Reprod Dev, 37:93-98. 